\title{
Capítulo
}

4

\section{Técnica de Ensino de Matemática para Alunos com Deficiência Visual com suporte Informatizado}

\author{
Angélica Fonseca da Silva Dias, José Antonio dos Santos Borges e Júlio \\ Tadeu Carvalho da Silveira
}

\begin{abstract}
This short course aims to introduce a methodology, easy to disseminate and reproduce, that produces better quality and comprehensiveness in the teaching of mathematics in inclusive classes with the visually impaired students. The course introduces techniques for writing and reading texts with mathematical and graphics content, with intensive use of specific computational tools that enable the formation of students, at the middle and higher levels, to meet acceptable criteria of quality and content, also favoring the access and permanence of blind and low vision students in math-based university careers.

\section{Resumo}

$O$ objetivo deste minicurso é apresentar uma metodologia de fácil reprodução e disseminação, que permite aumentar a qualidade e abrangência do ensino de matemática em classes inclusivas com alunos com deficiência visual. O curso introduz técnicas de escrita e leitura de textos com conteúdo e gráficos matemáticos, com uso intensivo de ferramentas computacionais especificas que propiciam que a formação dos alunos, tanto no nível médio quanto superior, obedeça a critérios aceitáveis de qualidade e conteúdo, favorecendo também o acesso e permanência de estudantes cegos e com baixa visão nas carreiras universitárias com base matemática.
\end{abstract}

ADVERTÊNCIA: para leitura e editoração correta deste texto é necessário ter instalada a fonte SimBraille no computador.

\subsection{A utilização de computadores por pessoas com deficiência visual}

Desde 2006, a Sociedade Brasileira de Computação (SBC), vem patrocinando estratégias que promovam o aumento do acesso participativo e universal do cidadão brasileiro ao conhecimento. Reconhecendo a grande quantidade de pessoas no país que 
convive com enormes diferenças sociais, financeiras, físicas e mentais, o que é levado em conta não é somente apoiar a produção de soluções inclusivas para adaptação de sistemas computacionais interativos para uso por pessoas com deficiência "que possam ser generalizados para múltiplos dispositivos", mas adequar os artefatos tecnológicos criados a esta enorme diversidade social. (Melo, A.M., 2014)

Nos últimos anos diversas áreas do ensino para pessoas com deficiência visual no Brasil utilizam cada vez mais sistemas computadorizados com síntese de voz para atender a alunos com deficiência visual. Os sintetizadores vêm pré-configurados para produzir uma fala razoavelmente precisa de textos convencionais na língua portuguesa, tanto em termos fonéticos quanto prosódicos, permitindo uma leitura fluente e agradável (Ferreira, 2014).

No Brasil, entre os sistemas de maior utilização está o Dosvox (NCE-2010), um sistema composto por cerca de 100 programas que atendem a grande parte das necessidades computacionais de uma pessoa com deficiência visual. Ele usa apenas a síntese de voz e o teclado para permitir a comunicação completa entre o computador e o usuário que não enxerga. Neste processo ele utiliza um estilo de comunicação muito intuitivo, baseado no uso de menus interativos falados, que conduzem o usuário por opções que são selecionadas através das setas do teclado ou por abreviaturas de uma única letra (Borges, 2009), O Dosvox não tenta simplesmente sonorizar os ícones e textos apresentados na tela, mas apresenta um diálogo sonoro facílimo de assimilar e de interagir, mesmo quando é usado por crianças pequenas ou pessoas com variados níveis de deficiência visual. (Dias et al 2016).

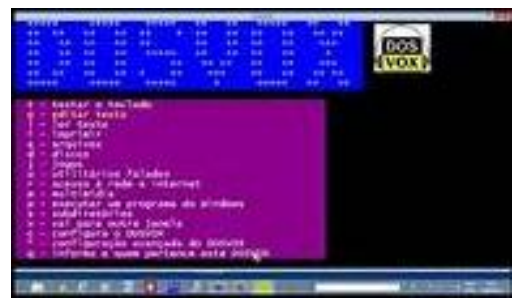

Figura 4.1 - DOSVOX

Por outro lado, esse diálogo específico tem que ser construído para cada função que deve ser oferecida. Isso o torna, por um lado, um sistema de operação muito simples, agradável e de rápida curva de aprendizado; por outro lado, à medida que a Informática evolui, novos programas precisam ser construídos, o que nem sempre ocorre, tanto por dificuldades técnicas quanto pelo esforço e recursos envolvidos.

Em direção oposta à operação simplificada do Dosvox, existem diversos programas conhecidos por "leitores de tela" no qual o teclado é usado para escolher interativamente e sonorizar um dos muitos elementos desenhados ou escritos na tela. A forma mais usual de operação é caminhar entre os itens desenhados usando as setas, caminhando sequencialmente entre os itens, ou a tecla TAB que pula para o próximo item clicável (link, por exemplo). É possível também usar sequências predefinidas de teclas (ou seja, teclas de atalho) que vai conduzindo o processo de leitura de lugares específicos do display (por exemplo, a barra de ferramentas) ou controlando uma leitura sequencial dos elementos (por exemplo, o texto de uma página da web).

Os leitores de tela mais usados no Brasil são o NVDA (produto gratuito, de origem australiana), o Virtual Vision (brasileiro) e o Jaws (americano). Mesmo tendo teclas de controle um pouco diferentes, comparativamente, seu uso não é muito diferente, até 
porque a sequência de navegação é predefinida pelos utilitários que eles estão lendo na tela e pelo sistema operacional.

A vantagem dos leitores de tela é que a operação é feita exatamente sobre o que está desenhado na tela. Mas, pelo fato de que a localização é feita sem ver, o usuário precisa ser treinado previamente em cada programa a utilizar, tendo em geral que decorar uma quantidade enorme de informações para um uso razoável do sistema. Em outras palavras, a curva de aprendizado é muito mais lenta, a operação é mais complexa, mas o acesso é mais completo.

Infelizmente, tanto o Dosvox quanto os leitores de tela não vem dando um suporte razoável para a escrita matemática a ser utilizada por cegos. A razão mais importante é que o texto matemático tem várias características peculiares, que não obedecem às regras de leitura e escrita usuais da língua portuguesa.

Em primeiro lugar, a escrita de matemática é tipicamente não linear, ou seja, escrevemse textos matemáticos com os elementos posicionados fora de uma linha única (há índices em cima, subíndices em baixo, frações, somatórios, etc.; em segundo lugar, ela exibe ambiguidades que exigem uma fala não coloquial, e muitas vezes peculiar. Por exemplo, $2^{1 / 2}$ (dois elevado a um meio) deve ser falado diferentemente de $21 / 2$ (dois inteiros e um meio). (ECS, 2015). (Dias et al, 2018).

\subsection{Cegos em carreiras com base matemática (STEM $\left.{ }^{\mathbf{1}}\right)$}

Observamos que, graças ao uso de tecnologia computacional, foi viabilizada a presença de pessoas cegas em muitos cursos universitários, especialmente naqueles em que os textos de suporte não são matemáticos, que ${ }_{2}$ já vimos, não vinham, até pouco tempo, sendo bem suportados. Infelizmente, isso não vale para as carreiras em que a matemática é um elemento central, em que o número de pessoas cegas cursando é próximo de zero.

Será que a razão é que o raciocínio exigido nas disciplinas aqui envolvidas é incompatível com as restrições impostas pela cegueira? Ou seria apenas a falta de suporte computacional adequado a causa principal de haver tão poucos estudantes cegos em cursos das carreiras com base matemática? (Cryer, 2013)

Há exemplos que desmentem a primeira conjectura. Talvez o mais impressionante seja o do matemático inglês Nicholas Saunderson (1682-1739), que viveu em uma época em que não havia tecnologia de escrita para cegos. Mesmo assim, ele é considerado um dos maiores matemáticos da história - pela Universidade de Cambridge (Reino Unido). É importante salientar que Saunderson era o que conhecemos hoje como superdotado, alguém capaz de formular e resolver equações matemáticas complexas mentalmente, sem usar a escrita para auxiliar o raciocínio (ver Wikipedia).

Uma pessoa mediana, entretanto, não consegue adquirir estas facilidades de abstração e cálculo mental senão com muitos anos de treinamento especializado. O que é necessário então é desenvolver um ferramental diferenciado, facilmente operável por pessoas cegas simples e até com baixa cultura, e que dê conta dos detalhes para permitir independência no estudo. É preciso que a pessoa, possivelmente com a ajuda do computador, seja capaz de escrever e ler textos matemáticos de mediana complexidade, sozinha e com segurança. 
Somente há pouco tempo é que estas soluções computacionais vêm aparecendo e trazendo muito boas perspectivas para os alunos com deficiência visual. Através delas, prevê-se a possibilidade de que, em pouco tempo, seja possível viabilizar a presença bem sucedida de uma pessoa cega em classes mistas, com total proficiência de leitura e escrita de textos envolvendo matemática de razoável complexidade.

\subsection{Apresentação dos principais temas estudados neste curso}

Este texto descreve as iniciativas computacionais com algumas soluções baseadas no uso de informática para o ensino de matemática para cegos e algumas questões relacionadas à educação inclusiva e aprendizagem colaborativa mediada por computador, entre alunos com ou sem deficiência visual.

Começamos com um breve apanhado sobre a escrita de matemática Braille, mostrando algumas vantagens e dificuldades deste método. Em seguida mostramos algumas formas de produzir mecanicamente (usando impressora Braille) um texto simples em Braille matemático, usando o Braille como forma de apresentação, constatando que mesmo esta automatização não tem conseguido contornar as dificuldades essenciais que esta técnica apresenta e está sujeita.

Mostramos em seguida as dificuldades existentes atualmente para que as formas usuais de escrita matemática convencionais no computador (editores de equações e as convenções de escrita $\mathrm{L}_{\mathrm{A}} \mathrm{T}^{\mathrm{E}} \mathrm{X}$ ) sejam utilizadas por pessoas cegas. Alternativamente, descrevemos a técnica de escrita baseada numa codificação especial acessível (AsciiMath), a leitura em síntese de voz com uma prosódia específica (SonoraMat).

Finalmente mostramos algumas questões relacionadas com a elaboração e leitura de gráficos pelos alunos, apresentando o Geoplano e o Multiplano como elementos importantes no aprendizado. Para operacionalização usando o computador, apresentamos uma ferramenta computacional criada especialmente para atender às demandas do desenho sem feedback visual (Grafivox).

Com o uso destes três mecanismos: o AsciiMath, SonoraMat e Grafivox, pretende-se que o cursista adquira habilidades para:

$>$ Dominar as técnicas de escrita matemática no computador, com ferramentas simples, adotando uma escrita linear (semelhante às expressões que os desenvolvedores de software inserem nos programas de computador, utilizando um simples editor de textos).

$>$ Ler sonoramente um texto matemático, escrito por qualquer pessoa (inclusive pelo próprio aluno). Este texto é reproduzido por fala sintetizada no computador, de forma inteligível e fluente.

$>$ Produzir gráficos matemáticos simples, de forma interativa, que podem ser reproduzidos em impressoras de alto-relevo, que serão facilmente "lidos" por alunos cegos, ou em forma impressa convencional, pelos alunos que enxergam.

Em síntese, este capítulo aborda, de maneira estruturada, alguns conceitos teóricos relacionados ao ensino de matemática para cegos, com a apresentação de técnicas computacionais ainda pouco conhecidas, que facilitam esta atividade, e que constituem o núcleo deste minicurso. A seção 4.4 apresenta um breve referencial teórico sobre as técnicas tradicionais de representação e manipulação de matemática por estudantes cegos, em particular, o Braille Matemático. A seção 4.5 apresenta brevemente dois estilos de uso do computador, mostrando que, em ambos, são grandes as dificuldades ao usar as técnicas de escrita de matemática que são comumente adotadas para usuários 
sem cegueira. A seção 4.6 aborda o AsciiMath, uma técnica simples de linearização da escrita matemática e o SonoraMath, complemento computacional que reproduz o texto escrito segundo regras prosódicas peculiares. A seção 4.7 apresenta o Geoplano e o Multiplano, ferramentas importantes para o domínio dos conceitos geométricos básicos. A seção 4.8 mostra uma alternativa para que os cegos sejam capazes de criar interativamente gráficos matemáticos simples no computador, o Grafivox. A Seção 4.9 contém uma breve discussão sobre os resultados alcançados com estas técnicas.

\section{4 - Representação e manipulação de matemática por pessoas cegas através do Braille}

Em 1824 Louis Braille, um estudante cego construiu um sistema eficaz de escrita e leitura autônomas para pessoas com deficiência visual. Com o advento da escrita Braille os cegos se tornaram proprietários de um competente sistema simbólico, e encontraram a ferramenta fundamental que lhes proporcionou uma revolução semiótica. Tal revolução aumentou significativamente a gama dos fenômenos, corpos e objetos que puderam então ser absorvidos para serem compartilhados com as pessoas que enxergam. (Souza, 2017).

O Braille é um sistema de transcrição que pode ser lido por toque. Nele, os caracteres são representados por conjuntos de seis pontos, numa matriz de 3 linhas e 2 colunas, que são conhecidos como células (também chamadas de celas, uma corruptela do inglês "cell"). Com 6 pontos é possível representar 63 arranjos, sem contar com o espaço, o que é suficiente para o alfabeto e muitos outros caracteres.

Para identificar os pontos dentro da célula usam-se números de 1 a 6 como na figura 4.2:

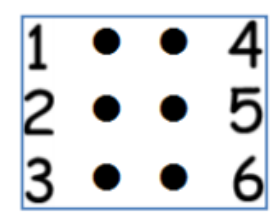

Figura 4.2 - pontos Braille

\subsubsection{Representação de caracteres em textos}

Louis Braille criou um código fácil de decorar, como mostrado a seguir:

a) Ele usou os 4 pontos superiores para as letras de a até j, eliminando algumas combinações que seriam difíceis de identificar, sendo cego. Por exemplo, ele usou apenas o pontinho 1 para representar a letra a, mas deixou de lado a possibilidade de usar só o pontinho 2 ou só o 4 ou só o 5 , pois o leitor se confundiria. Veja as escolhas de Braille:

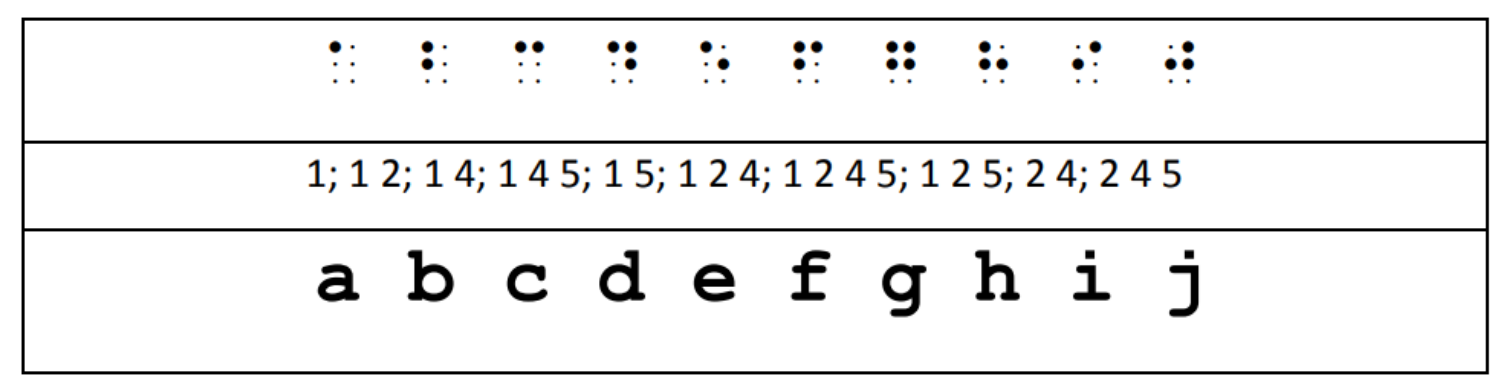


b) Todas as letras até agora não usaram a linha inferior. Então Braille usou a mesma sequência de pontos agregado ao ponto 3 para as próximas 10 letras. Em seguida agregou os pontos 3 e 6 para as letras restantes.

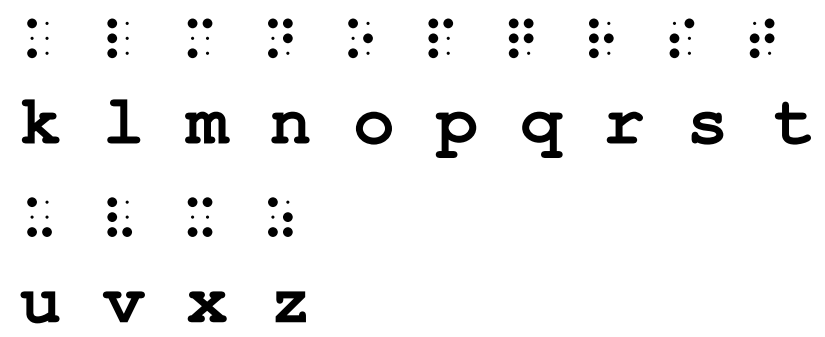

Nota: o w é exceção: :: pois não existia em francês naquela época.

c) Indicar maiúsculas também é simples: basta usar os pontos 4 e 6 antes da

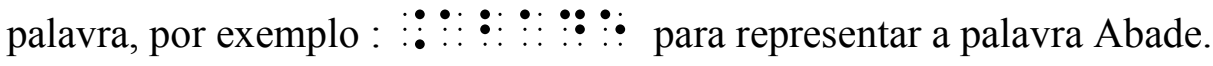

Duas vezes este símbolo indica uma palavra em caixa alta: para representar a palavra ABADE.

d) Acentos: Bem... Acentos não seguem uma regra tão simples: as letras mais os acentos são representados por códigos especiais. Pior que isso, dependendo da língua, são diferentes. Veja na tabela 1 abaixo a relação completa de letras, inclusive, os acentos.

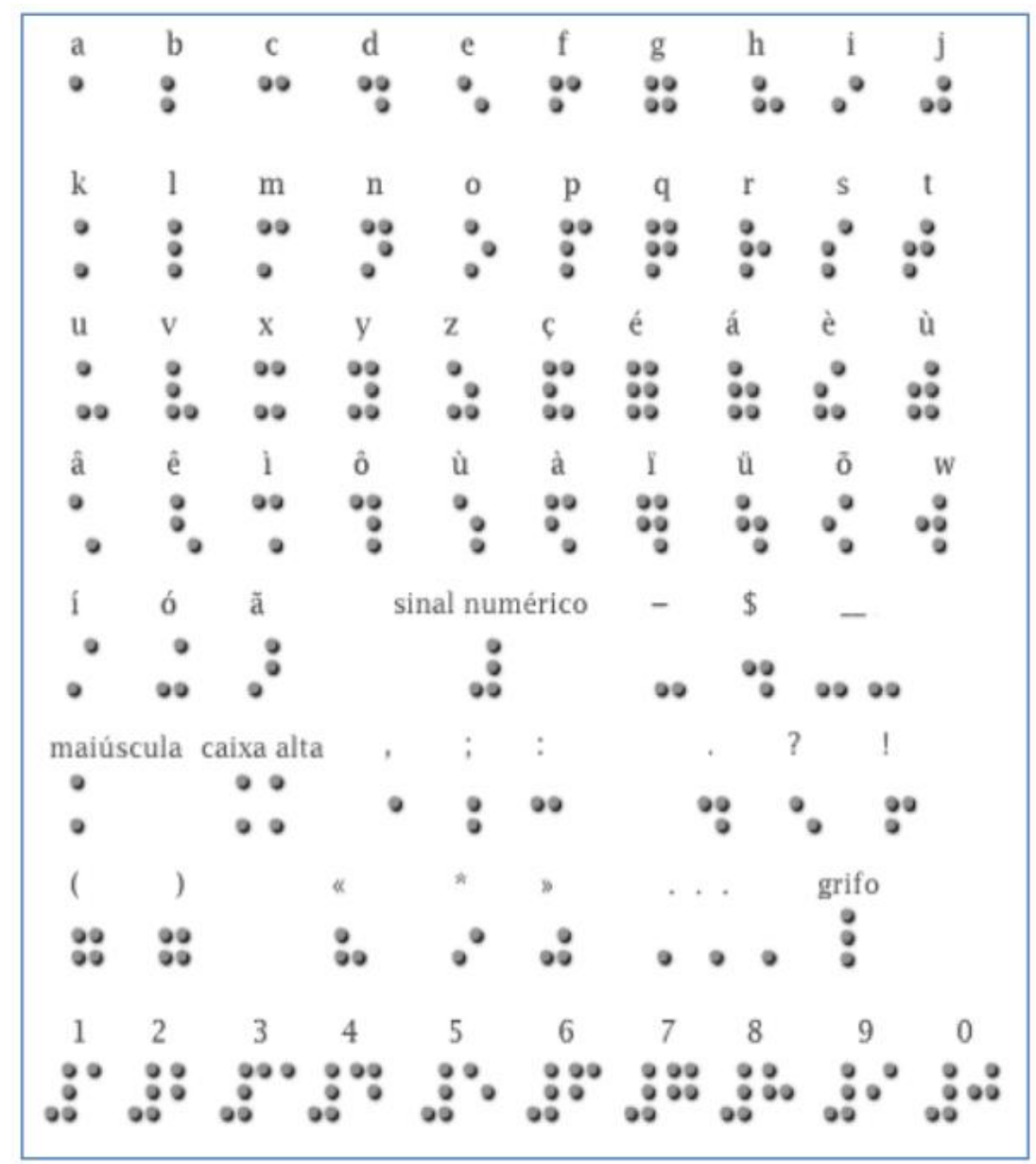

Tabela 1 - códigos Braille usados no Brasil 
A escrita Braille pode ser feita manualmente utilizando um dispositivo chamado Reglete, no qual se pressiona um Punção, como visto na figura 4.3. Neste dispositivo, se cria os pontos da direita para a esquerda, de forma que, ao virar o papel, eles estejam com os pontos em relevo para a direita. Opcionalmente pode-se utilizar uma máquina de escrever especial, como mostrado na figura 4.4.

A prática da escrita manual, entretanto, vai além dos objetivos deste curso.

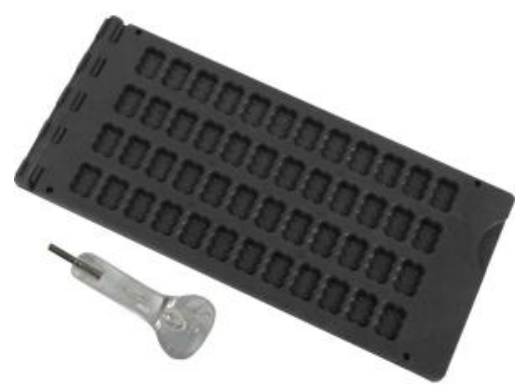

Figura 4.3 - Reglete e Punção

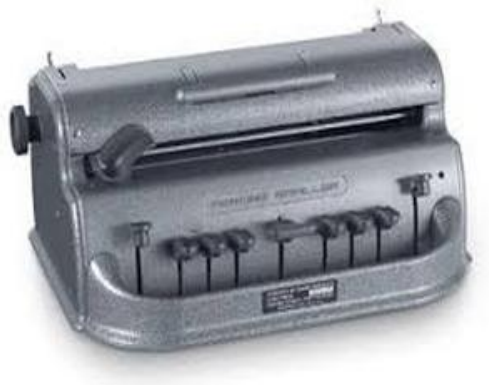

Figura 4.4 Máquina de escrever em Braille

\subsubsection{Representação de matemática}

A representação de símbolos matemáticos é simples.

a) Para representar os dígitos numéricos, usam-se as letras de a até j em Braille, sendo o número precedido por um sinal \# (pontos 3456 ).

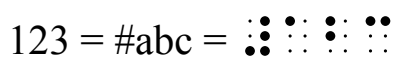

b) O ponto e a vírgula decimais são hoje representados, respectivamente pelos | pontos 3 e 2 .

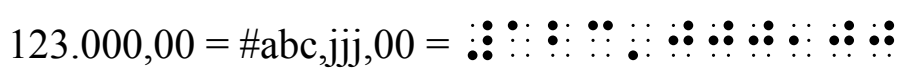

c) Símbolos aritméticos

$\because \quad\left(\begin{array}{l}\vdots \\ \vdots\end{array}\right): \vdots$

d) Representação de expressões

Esta mesma técnica, com pequenas adaptações, permite a transcrição de expressões matemáticas que precisam ser adaptadas com um processo algorítmico que inclui sua linearização (que pode incluir parênteses), como está ilustrado na Figura 4.5.

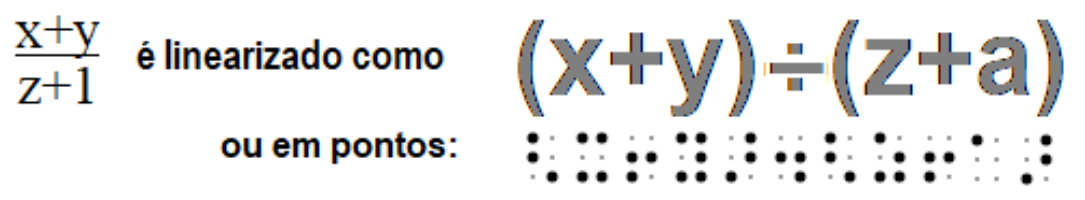

Figura 4.5: Expressão matemática simples e sua conversão para Braille.

e) Frações numéricas: abaixa-se os pontos do número do dividendo 


\section{2/3 : : : : : : :}

Detalhe técnico:

Ao linearizar expressões é comum ter que adicionar parênteses que não existiam na expressão original. Neste caso é conveniente usar nestes parênteses uma codificação especial, com os pontos

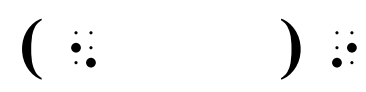

\begin{tabular}{l}
\hline IMPORTANTE: O BRAILLE MATEMÁTICO NÃO É UNIVERSAL \\
Todos os símbolos matemáticos têm equivalência em Braille, mas devemos \\
notar que os códigos de Braille matemático usados não são universais. No \\
Brasil, por exemplo, adotou-se um código unificado com a Espanha e Portugal \\
(Anjos, 2016), o que trouxe sérias consequências, como a dificuldade em usar \\
a ampla literatura em Braille americano (Nemeth Code) (NBA, 1972) e a \\
impossibilidade de usar os vários programas para transcrição \\
computadorizada para matemática em Braille.
\end{tabular}

\subsubsection{Um pequeno exercício usando a folhinha de treinamento}

Disponibilizamos uma folha na Internet, em que os pontos Braille foram marcados como pequenas bolinhas. Desta forma é fácil treinar usando lápis e borracha.

Baixe e imprima esta folhinha a partir da página do link:

http://intervox.nce.ufrj.br/ antonio2/cursobraille/folhinha braille.pdf

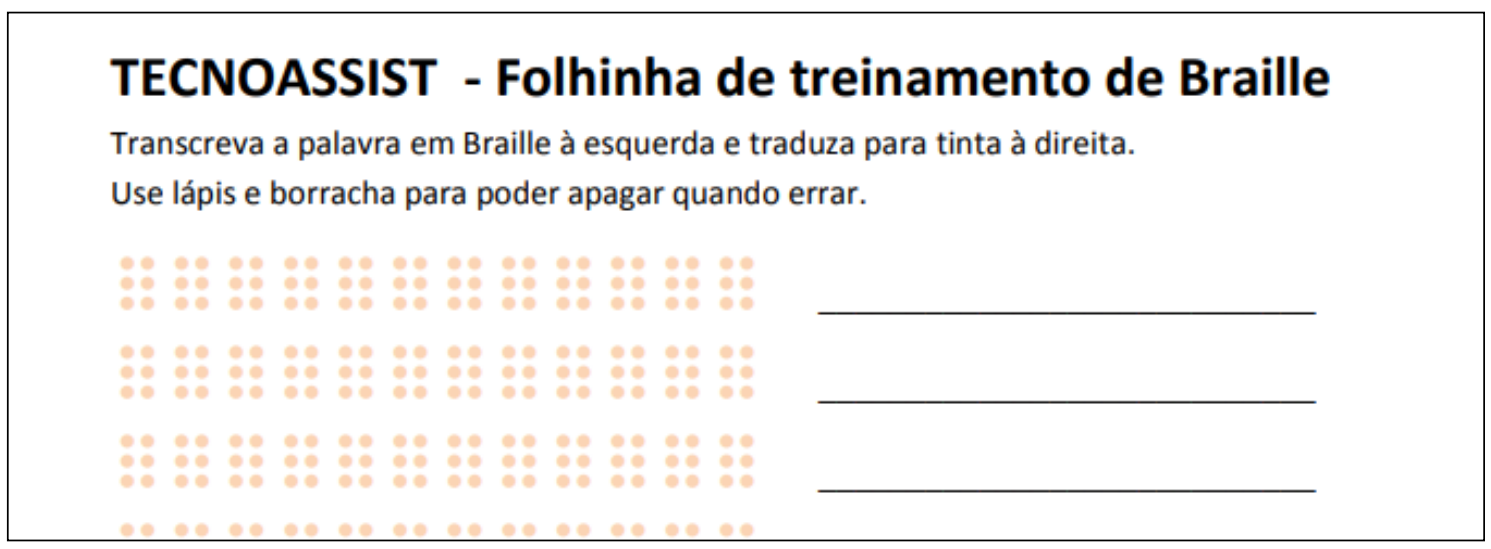

Figura 4.6: Folhinha de treinamento Braille

Produza na folhinha de treinamento usando um lápis para marcar os pontinhos Braille:

$1+2=3$

$(2+4) \times 3=12$

$5 \div 2=2,5$ 


\section{$2 / 3$ \\ $1 / 3+1 / 2=5 / 3$}

\subsubsection{Impressão computadorizada de Braille}

No Brasil, houve ampla disponibilização de impressoras computadorizadas de Braille promovidas pelo MEC como parte do Plano Nacional do Livro Didático em Braille (Borges, 2001). Foram criadas também ferramentas tecnológicas automáticas para transcrição com rapidez e boa usabilidade, como o Braille Fácil. (ver figura 4.7).

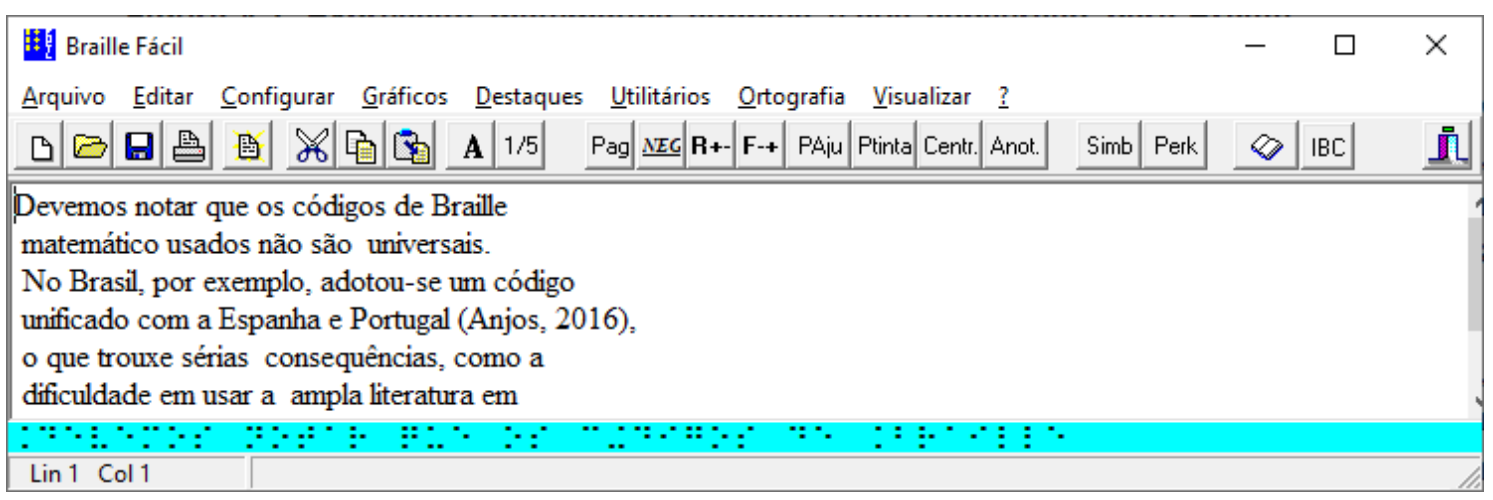

Figura 4.7 - Programa Braille Fácil

O uso deste programa é quase trivial. Simplesmente se digita o texto na tela e seleciona-se a opção de Arquivo/Imprimir em Braille. Naturalmente, é necessário que ao computador esteja acoplada uma impressora Braille. O uso do programa Braille Fácil transcende os objetivos deste curso.

Um detalhe: alguns símbolos matemáticos na forma textual diferem dos símbolos usuais de texto simples. Para evitar discrepâncias na tradução para Braille, o programa permite que todos os símbolos matemáticos sejam desambiguados simplesmente precedendo-os pelo sinal de crase (').

\subsubsection{O declínio da escrita Braille}

A disponibilidade das ferramentas tecnológicas ajudou a incrementar a produção de textos em Braille, mas não impediu o declínio da utilização desta técnica no país. Este é um fenômeno mundial, provocado pelo uso cada vez mais intenso do computador e outros dispositivos similares associado a ferramentas de acessibilidade. Por exemplo, nos Estados Unidos, estimava-se que na década de 1950, 40 por cento das pessoas cegas tinha contato com o Braille. Em 2009, menos de 10 por cento das crianças cegas o aprendia [NFB, 2009].

No Brasil, o ensino da matemática para cegos, até poucos anos atrás, vinha utilizando como suporte a escrita Braille, que embora seja intrinsecamente unidimensional, é capaz de prover mecanismos de manipulação de textos não lineares. Mas há uma grande dificuldade: além do declínio do conhecimento de Braille pelos alunos, também é raro que os professores das classes convencionais estejam habilitados para esta forma de escrita e leitura. 
Desta forma, nós recomendamos a escrita matemática em Braille na escola nos primeiros anos, em particular no ensino da matemática básica, pois essa forma de escrita tem a tendência de gerar um contato mais íntimo com a matemática e um aumento na abstração, na medida em que existe um consenso de que o processo de escrita Braille favorece o contato íntimo com os símbolos o que se traduz numa relação mais íntima com a matemática, fundamental no ensino básico. Entretanto, quando se trata de um ensino mais avançado, que exige interação com o professor e com os colegas num nível mais complexo, e usando textos de certo tamanho, o uso do computador é bem mais eficiente.

\section{5 - A escrita tradicional de matemática no computador e seus elementos de inacessibilidade para cegos}

Existe uma preponderância de editores de textos para literatura, mas um número muito reduzido de ferramentas para escrita de textos matemáticos. Isso vale também quando se trata de pessoas com deficiência visual.

A maior parte das pessoas que enxergam faz uso de duas formas de escrever matemática:

a) usando uma codificação textual simples com marcações (conhecida como $\left.\mathrm{L}_{\mathrm{A}} \mathrm{T}^{\mathrm{E}} \mathrm{X}\right)$

b) montando as fórmulas matemáticas com suporte de um editor gráfico, usando o mouse, com o qual se vai posicionando interativamente os símbolos num painel na tela do computador. Um exemplo é o Equation Editor do Microsoft Word.

A escrita em $\mathrm{L}_{\mathrm{A}} \mathrm{T}^{\mathrm{E}} \mathrm{X}$ é conceitualmente simples: utiliza-se um editor comum de textos, usando os caracteres $+-* /=$ para os símbolos aritméticos usuais. O restante dos símbolos matemáticos e as indicações de posicionamento gráfico são representados pela $\backslash$ (barra invertida) seguida por uma palavra-chave. A figura a seguir ilustra o texto digitado e sua representação quando o texto for impresso por um utilitário de conversão.

$\backslash[$

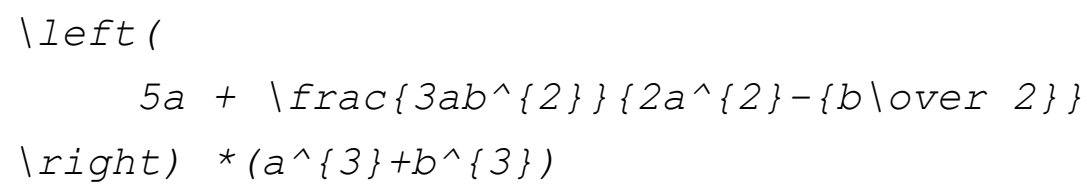

que representa

$$
\left(5 a+\frac{3 a b^{2}}{2 a^{2}-\frac{b}{2}}\right) *\left(a^{3}+b^{3}\right)
$$

Figura 4.8: Representação $L_{A} T^{E} X$ de uma expressão matemática

Frisamos que a escrita textual simples do $\mathrm{L}_{\mathrm{A}} \mathrm{T}^{\mathrm{E}} \mathrm{X}$ pode ser executada sem dificuldade usando qualquer editor de textos simples, em particular o Sistema Dosvox. Entretanto, o texto escrito apresenta uma forma de escrita muito rebuscada, tornando sua leitura árdua e sujeita a interpretações equivocadas quando realizada através de um sintetizador 
de voz. Já a leitura da produção de editores gráficos de matemática não é suportada pelo Dosvox.

A alternativa são os softwares leitores de tela, que são capazes de reproduzir o conteúdo que está escrito na tela, dando também suporte interatividade neste conteúdo, possivelmente usando o mouse ou o teclado. Porém, estes softwares também dão suporte muito limitado à leitura da tela quando ela apresenta textos matemáticos e quando se utilizam editores gráficos para matemática.

Como alternativa, Silveira et al. (2011) apresentaram um artefato tecnológico capaz de elaborar material instrucional com símbolos matemáticos, sendo estes convertidos automaticamente para o formato texto, que pode ser reproduzido pelos leitores de tela. Além disso, essa ferramenta pode gerar o mesmo conteúdo no formato MathML (formato textual, semelhante a HTML, usado pelos navegadores de internet para apresentar visualmente textos matemáticos). No entanto, o estudo realizado sobre este artefato mostra algumas limitações como a navegação em fórmulas extensas e a incorporação desses componentes em um ambiente mais versátil para editoração do que os navegadores Web.

\section{6 - Alternativas de escrita e leitura de matemática por cegos: o AsciiMath e o SonoraMat}

Simplificando, existem dois problemas mais importantes para o aluno cego quando o assunto é matemática:

1. Escrever matemática no computador, com ferramentas simples, usando uma escrita linear (algo semelhante ao que os programadores fazem quando criam programas convencionais em um editor de textos de linhas de comando).

2. Ler um texto matemático escrito por ele próprio ou por outras pessoas, traduzindo o texto criado para uma fala que o representasse de forma clara.

O Dosvox era, até pouco tempo atrás, frágil quando o assunto era suporte à matemática. Tinha algumas ferramentas específicas, como calculadora sonora e planilha especializada, mas elas não davam suporte razoável à escrita de matemática e à operacionalização de cálculos matemáticos mais sofisticados. 
VI Escola Regional de Sistemas de Informação. ISBN: 978-85-7669-488-5
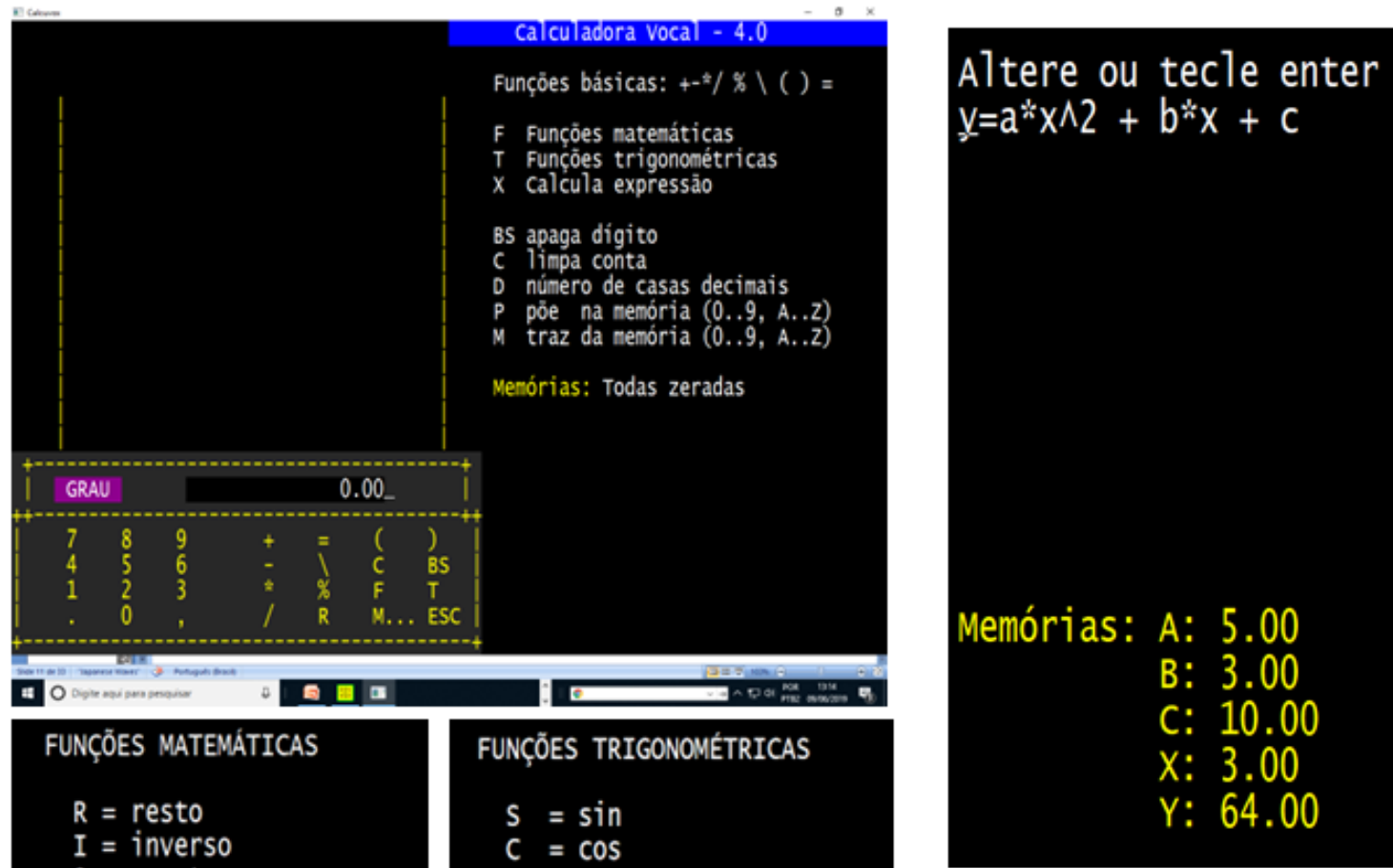

\section{FUNÇ̄̃ES MATEMÁTICAS}

$R=$ resto

$\mathrm{I}=$ inverso

$0=$ oposto

$\mathrm{T}=$ truncar

$A=$ arredondar

$\mathrm{F}=$ fracionária

$\mathrm{P}=$ número pi

$\mathrm{E}=$ número de Neper

$\mathrm{L}=\log$

$\mathrm{N}=\log$ neperiano

$!=$ fatorial

$\Lambda=$ elevado a

$\backslash$ = raiz enésima
FUNÇÕES TRIGONOMÉTRICAS

$S=\sin$

$\mathrm{C}=\cos$

$\mathrm{T}=\tan$

$G$ = ângulos em graus

$\mathrm{R}=$ ângulos $\mathrm{em}$ radianos

AS $=\arcsin$

$A C=\arccos$

AT $=\arctan$

$\mathrm{HS}=\sinh$

$\mathrm{HC}=\cosh$

HT $=\tanh$

IS $=\sinh -1$

IC $=\cosh -1$

$\mathrm{IT}=\tanh -1$

Figura 4.9 - Calculadora sonora do Dosvox

Nota: Uma importante abordagem foi criada e usada com sucesso por diversos alunos de nível médio e superior, tendo por base o estilo de interface do Dosvox: o MatVox (Silveira, 2010), que agrega facilidades de cálculo matemático a um editor de textos. Porém, o problema de leitura de matemática convencional, também não foi resolvido por esta abordagem.

Um breve exercício:

Ative a calculadora sonora do Dosvox, usando as letras UC. Coloque na memória X da calculadora o valor 5 e depois calcule o valor da expressão: $x^{2}+2 x+3$

4.6.1 Como um cego criaria um texto contendo expressões matemáticas no computador? 
As alternativas mais óbvias para uma pessoa cega criar matemática, portanto seriam os formatos LaTeX, usados por $90 \%$ dos matemáticos para gerar textos científicos, ou o MathML (que não está sendo apresentado aqui), usado pelos navegadores da web para mostrar textos matemáticos. Infelizmente, ambos são complicados de escrever e sua leitura usando síntese de voz, é quase ininteligível.

Uma terceira alternativa foi escolhida: o formato AsciiMath (Gray, 2007), uma forma fácil de escrever matemática para a qual a renderização (geração do gráfico em papel) é compatível com todos os navegadores da atualidade. Este formato é similar à escrita de fórmulas matemáticas de linguagens de computação como Fortran ou Python, ensinadas nos cursos STEM.

Os principais símbolos de AsciiMath são os seguintes:

+ - * / = ( ) para os símbolos matemáticos básicos

sqrt para raiz quadrada

sum para somatório

$\wedge$ para representar a situação em que um símbolo sobe (por exemplo, num expoente)

_ para representar quando um símbolo desce.

Importante: o gerador de renderização gráfica elimina os parênteses que são colocados apenas para agrupamento, por exemplo $2^{\wedge}(\mathrm{x}+\mathrm{y})$ seria desenhado por $2^{\mathrm{x}+\mathrm{y}}$

Isso é verdade também quando representamos frações.

Por exemplo, uma equação do segundo grau: $x^{\wedge} 2+b x+c=0$

A figura 4.10 mostra um exemplo mais completo.

sum_(i=1)^n $i^{\wedge} 3=((n(n+1)) / 2)^{\wedge} 2$

$$
\sum_{i=1}^{n} i^{3}=\left(\frac{n(n+1)}{2}\right)^{2}
$$

Figura 4.10: Fórmula digitada em AsciiMath e renderizada

Essa solução foi integrada ao Sistema Dosvox, que, a partir de 2018, passou a editar e imprimir fórmulas matemáticas de grande complexidade, misturadas a textos comuns, bastando para isso que os textos em AsciiMath fossem precedidos e sucedidos por um caractere especial (acento grave), de forma que seja fácil distinguir o que é texto e o que é matemática. Falaremos em seguida sobre a sua impressão. 


\section{Símbolos especiais de AsciiMath}

AsciiMath suporta praticamente todos os símbolos matemáticos usados no ensino superior. A tabela 2 a seguir apresenta alguns dos mais utilizados, inclusive a sua equivalente em $\operatorname{LAT}^{\mathrm{E}} \mathrm{X}$

\begin{tabular}{|c|c|c|}
\hline Type & TeX alt & See \\
\hline+ & & + \\
\hline- & & - \\
\hline * & cdot & . \\
\hline 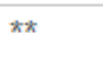 & ast & * \\
\hline$\star \star \star \star$ & star & $\star$ \\
\hline // & & / \\
\hline 11 & $\begin{array}{l}\text { backslash } \\
\text { setminus }\end{array}$ & $\backslash$ \\
\hline$x x$ & times & $\times$ \\
\hline$\therefore$ & div & $\div$ \\
\hline $1><$ & Itimes & $\ltimes$ \\
\hline$><1$ & rtimes & $\rtimes$ \\
\hline $\mid><1$ & bowtie & $\bowtie$ \\
\hline$@$ & circ & o \\
\hline $0+$ & oplus & $\oplus$ \\
\hline $\mathrm{ox}$ & otimes & $\otimes$ \\
\hline 0. & odot & $\odot$ \\
\hline sum & & \\
\hline prod & & \\
\hline$\wedge \wedge$ & wedge & $\wedge$ \\
\hline$\wedge \wedge \wedge$ & bidwedge & $\Lambda$ \\
\hline vV & vee & V \\
\hline VVV & bigvee & V \\
\hline $\mathrm{nn}$ & cap & $\cap$ \\
\hline
\end{tabular}

\begin{tabular}{|c|c|c|}
\hline Type & TeX alt & See \\
\hline $2 / 3$ & $\operatorname{frac}\{2\} 3\}$ & $\frac{2}{3}$ \\
\hline $2^{\wedge} 3$ & & $2^{3}$ \\
\hline sqrt $x$ & & $\sqrt{x}$ \\
\hline $\operatorname{root}(3)(x)$ & & $\sqrt[3]{x}$ \\
\hline int & & $\int$ \\
\hline oint & & $\oint$ \\
\hline del & partial & $\partial$ \\
\hline grad & nabla & $\nabla$ \\
\hline+- & $\mathrm{pm}$ & \pm \\
\hline $\mathrm{O} /$ & emptyset & $\emptyset$ \\
\hline Oo & infty & $\infty$ \\
\hline aleph & & $\aleph$ \\
\hline$\therefore$ & therefore & $\therefore$ \\
\hline$:^{\prime}$ & because & $\because$ \\
\hline$|\ldots|$ & |ldots| & $|\ldots|$ \\
\hline |cdots| & & $|\cdots|$ \\
\hline vdots & & $\vdots$ \\
\hline ddots & & $\ddots$. \\
\hline |M & & $1 \mid$ \\
\hline |quad| & & 11 \\
\hline I_ & angle & $\angle$ \\
\hline
\end{tabular}

\begin{tabular}{|l|l|l|}
\hline Type & TeX alt & See \\
\hline$=$ & & $=$ \\
\hline != & ne & $\neq$ \\
\hline$<$ & It & $<$ \\
\hline$>$ & gt & $>$ \\
\hline$<=$ & le & $\leq$ \\
\hline$>=$ & ge & $\geq$ \\
\hline$-<$ & prec & $\prec$ \\
\hline$-<=$ & preceq & $\preceq$ \\
\hline$>-$ & succ & $\succ$ \\
\hline$>-=$ & succeq & $\succeq$ \\
\hline in & & $\in$ \\
\hline !in & notin & $\notin$ \\
\hline sub & subset & $\subset$ \\
\hline sup & supset & $\supset$ \\
\hline sube & subseteq & $\subseteq$ \\
\hline supe & supseteq & $\supseteq$ \\
\hline$-=$ & equiv & $\equiv$ \\
\hline$\sim=$ & cong & $\cong$ \\
\hline$\sim \sim$ & approx & $\approx$ \\
\hline prop & propto & $\propto$ \\
\hline & & \\
\hline
\end{tabular}

Tabela 4.2 - Alguns símbolos de AsciiMath

Nota: A relação completa de símbolos pode ser encontrada em www.asciimath.org 


\section{Renderizando AsciiMath}

Existem alguns programas de uso público na internet capazes de renderizar textos em AsciiMath, mas nós optamos por criar um editor bem simples, que pudesse ser utilizado por alunos cegos e também por seus professores e colegas que enxergam para gerar textos matemáticos com grande beleza gráfica. Este programa pode também ser utilizado acoplado a leitores de tela.

Com o Intermat, uma pessoa qualquer consegue gerar textos matemáticos com grande beleza quando impresso, e que apresenta acessibilidade para deficientes visuais. $\mathrm{O}$ programa também aceita códigos HTML, que são simples e muito conhecidos, para diminuir a curva de aprendizado dos estudantes, como mostrado na figura abaixo.

Nota: Repare a inclusão de marcações para destaque gráfico em HTML (h2 e h3) e o uso de crases para indicar os trechos contendo códigos de matemática.

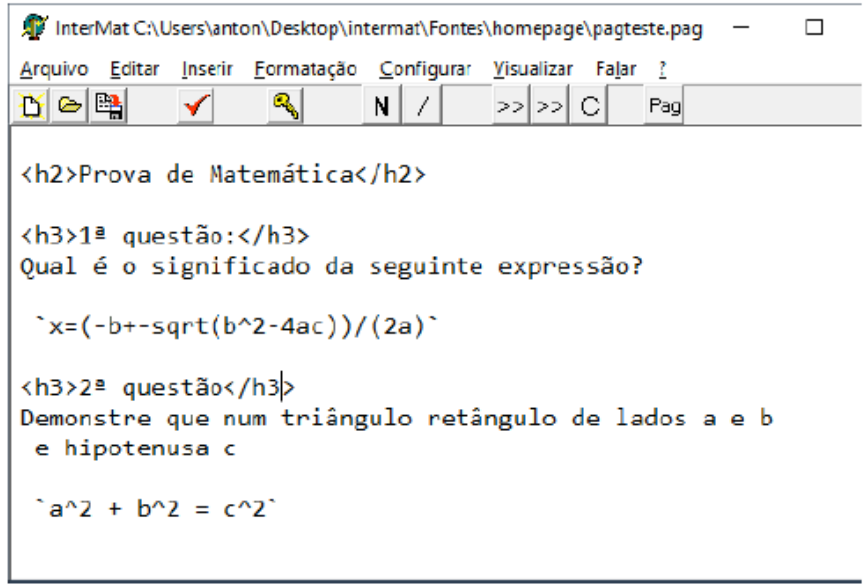

Figura 4.11: Um trecho de prova criado no InterMat (ou no Dosvox)

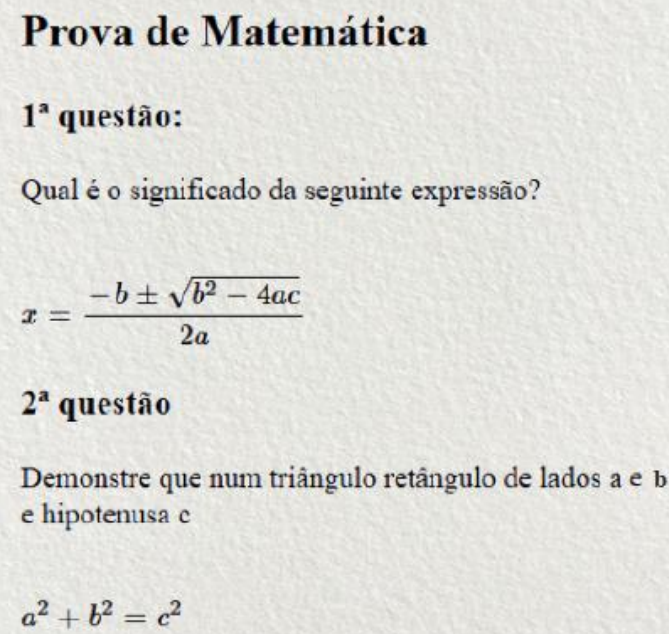

Figura 4.12: Impressão na tela ou papel através do InterMat 


\section{Um breve exercício:}

Instale o programa InterMat no seu computador, digite e visualize a as seguintes expressões matemáticas:

$$
\begin{aligned}
& a x^{2}+b x+c=0 \\
& a_{1} x^{2}+a_{2} x+c=0 \\
& x^{\prime}=\frac{-b+\sqrt{\Delta}}{2 \cdot a} \\
& x^{\prime \prime}=\frac{-b-\sqrt{\Delta}}{2 \cdot a}
\end{aligned}
$$

Digite esta mesma última fórmula expandindo Delta para $b^{2}-4 a c$

\section{Lendo AsciiMath num sintetizador de voz}

Apesar da simplicidade e conveniência deste formato, Ainda que um cego, devidamente orientado, possa escrever matemática com grande precisão e beleza com o AsciiMath, ele não conseguiria ler uma fórmula razoavelmente complexa de forma fluente e compreensível. Para isso foi desenvolvido no NCE/UFRJ o SonoraMat, uma ferramenta de leitura e elaboração de textos matemáticos. O SonoraMat é um programa acessório que quando executado, interage com Dosvox, Intermat e outros programas para interpretar a fala das expressões matemáticas.

Operação:

1. execute o programa SonoraMat

2. execute o Edivox ou SonoraMat.

3. Aperte as letras ALT-H para conectar os programas ao SonoraMat. Esta operação é feita apenas uma vez antes da primeira leitura do texto.

4. digite as expressões matemáticas precedendo-as e sucedendo-as com o sinal de crase.

5. Use os procedimentos normais para leitura, por exemplo, usando as setas.

6. Ao final, feche o programa SonoraMat

Nota:

Todos os textos matemáticos serão interpretados automaticamente no Dosvox ao usar as setas. No Intermat, que não é um programa tipicamente sonoro, é preciso ativar a configuração de fala automática das linhas, e neste caso as expressões serão faladas junto com as teclas Cima e Baixo deste editor.

\section{Um breve exercício:}

Leia em síntese de voz os resultados do exercício anterior, usando o Intramat ou o Editor Edivox do sistema Dosvox.

Para isso, instale antes o Sonoramat no computador a partir do site: 


\subsection{O Geoplano e o Multiplano}

Antes de ensinar uma pessoa cega a desenhar é importante passar para ela alguns conceitos básicos de geometria, sendo o Geoplano uma ótima ferramenta. Este objeto é formado por uma placa de madeira onde são cravados pregos, fomando uma malha composta por linhas e colunas dispostas de acordo com a figura a seguir:
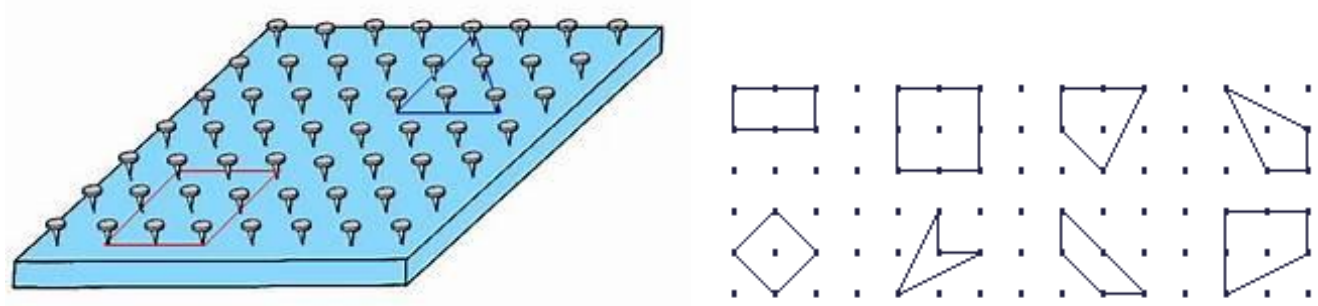

Figura 4.13 - Geoplano e alguns desenvolvimentos

O Geoplano introduz a pessoa cega à Geometria Euclidiana, em particular ao Plano Cartesiano. Ele pode ser utilizado para construir figuras simples, unindo os preguinhos por elásticos, como na figura a seguir. $O$ Geoplano também é muito útil para desenvolver estratégias para cálculo de perímetro, área, figuras simétricas, arestas, vértices, construção de polígonos, exploração espacial entre outros.

Exercício:

Use um geoplano para:

- Construir dois quadrados de áreas diferentes.

- Calcular a área e o perímetro de cada figura.

- Dividir os quadrados em triângulos de mesma área.

- Descobrir a área de cada triângulo encontrado.

- Construir um retângulo de área igual a 12

Provavelmente você não terá acesso a um geoplano real (embora seja muito fácil adquirir um através da Internet). Mas você pode usar um geoplano virtual:

\section{https://apps.mathlearningcenter.org/geoboard/}

Devemos finalmente, indicar que há iniciativas importantes que se apresentam como alternativas ao Geoplano. Destacamos o Multiplano, dispositivo inventado por Rubens Ferronato em sua tese de mestrado, e posteriormente industrializado. [Ferronato, 2002]. 

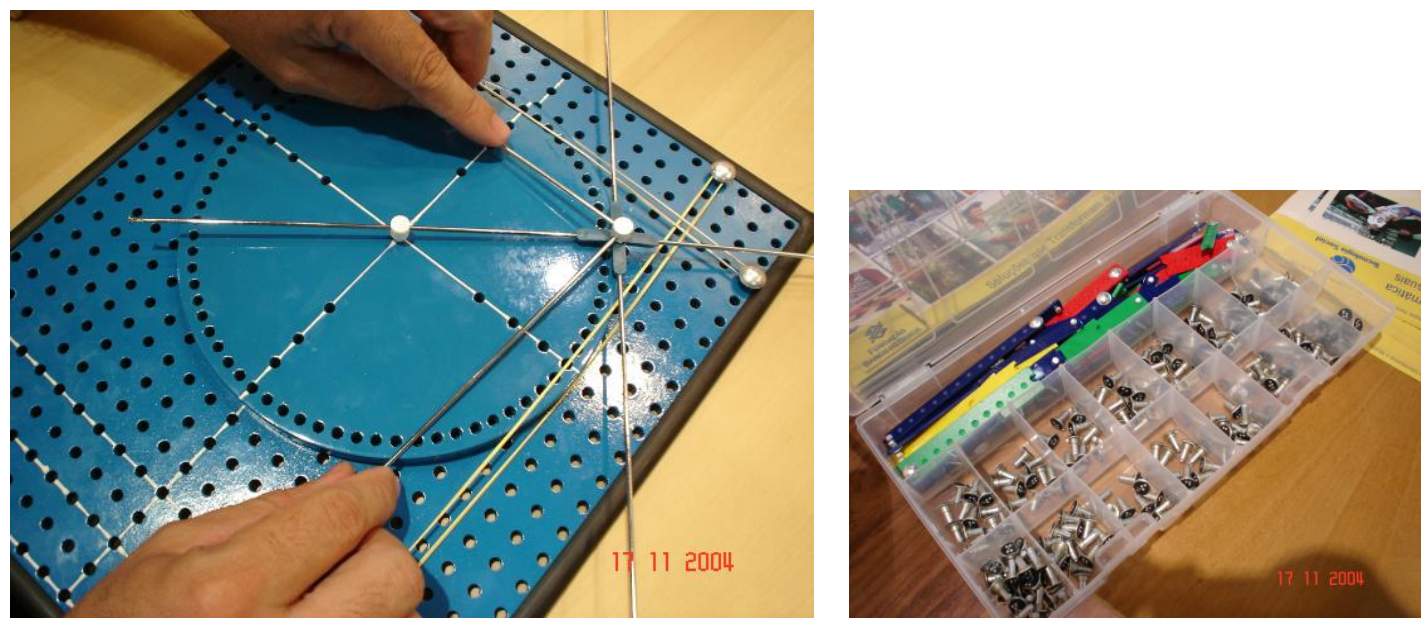

Figura 4.14 - 0 multiplano e algumas de suas peças

O Multiplano é base de uma metodologia cujos resultados são apontados como muito efetivos em vários níveis de ensino (da pré-escola à universidade). Entretanto o estudo desta ferramenta transcende os objetivos deste texto, especialmente pelo nosso foco no suporte computacional ao ensino de matemática para cegos.

\subsection{Criação interativa de gráficos por pessoas cegas}

Em matemática, o desenho é crucial para complementar e compreender a informação escrita. Quanto mais técnica ou complexa é a expressão matemática, mais a sua representação gráfica se firma como uma linguagem na qual podemos expressar ideias e conceitos de maneira concisa, clara e interessante. Até pouco tempo atrás, porém, as tecnologias disponíveis de desenho para cegos permitiam apenas a leitura ou a escrita indireta ou com interveniência de outros dispositivos. A verdade é que os cegos não têm sido estimulados a desenhar os gráficos, apenas consumi-los.

Estudos demonstram que a partir de experiências com alunos cegos (Borges, 1998), pode-se produzir, com treinamento mínimo, gráficos legíveis - para pessoas cegas ou não. Isto, entretanto, só se viabilizou pela disponibilidade das impressoras Braille e das máquinas fusoras, hoje presentes em centros de apoio pedagógico nas escolas e universidades públicas.

Com a entrada de estudantes cegos em carreiras STEM, na UFRJ, tornou-se urgente viabilizar que os alunos conseguissem produzir gráficos simples para apresentar em seus trabalhos universitários. Para isso, foi agregado ao sistema Dosvox um utilitário que, através de uma pequena linguagem gráfica pudesse produzir gráficos simples, compostos por elementos básicos (linhas, curvas, funções, eixos, etc). O programa Grafivox é capaz de reproduzir, na tela ou numa impressora em tinta ou Braille, o desenho produzido, automaticamente escalonado e adaptado às características daqueles equipamentos (que no caso das impressora Braille são bastante distintos, pela baixíssima resolução que apresentam). É possível também gravar a forma gráfíca gerada em PNG ou JPG, para importação num editor de textos ou outro utilitário qualquer.

A linguagem gráfica que foi desenvolvida, também denominada de Grafivox, foi tornada também compatível com o sistema Intermat, possibilitando desta forma que os textos matemáticos criados ou exibidos por aquele utilitário pudessem ter ilustrações gráficas. 
A interação do programa é trivial, e como a maior parte dos programas do Dosvox, baseada num menu, controlado pelas setas, para escolha da função desejada: edição (interativa ou por edição direta), visualização, impressão e configuração, como mostrado na figura 4.15 .

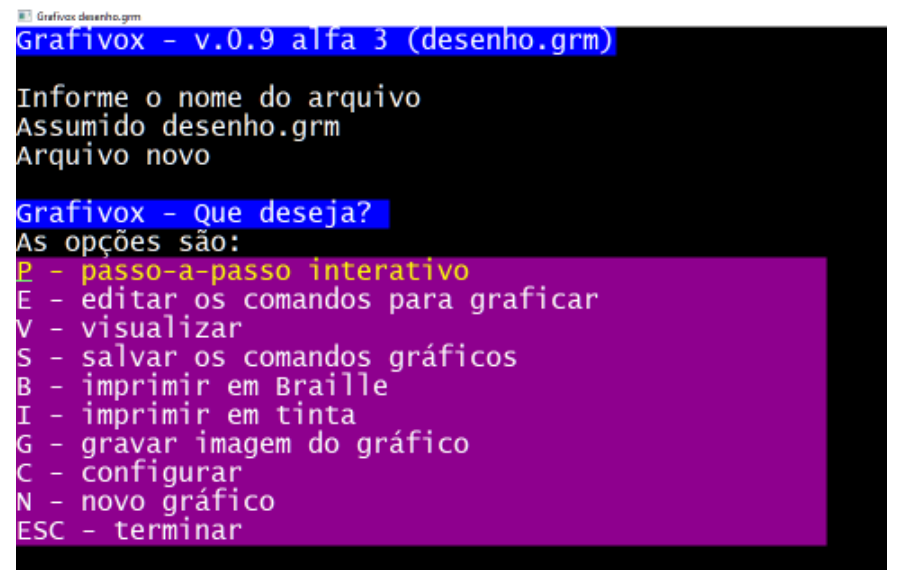

Figura 4.15: Opções gerais do programa Grafivox

\subsubsection{A linguagem Grafivox}

A figura 4.16 mostra à esquerda um pequeno programa escrito no Grafivox, e à direita, o resultado impresso em tinta e em Braille.

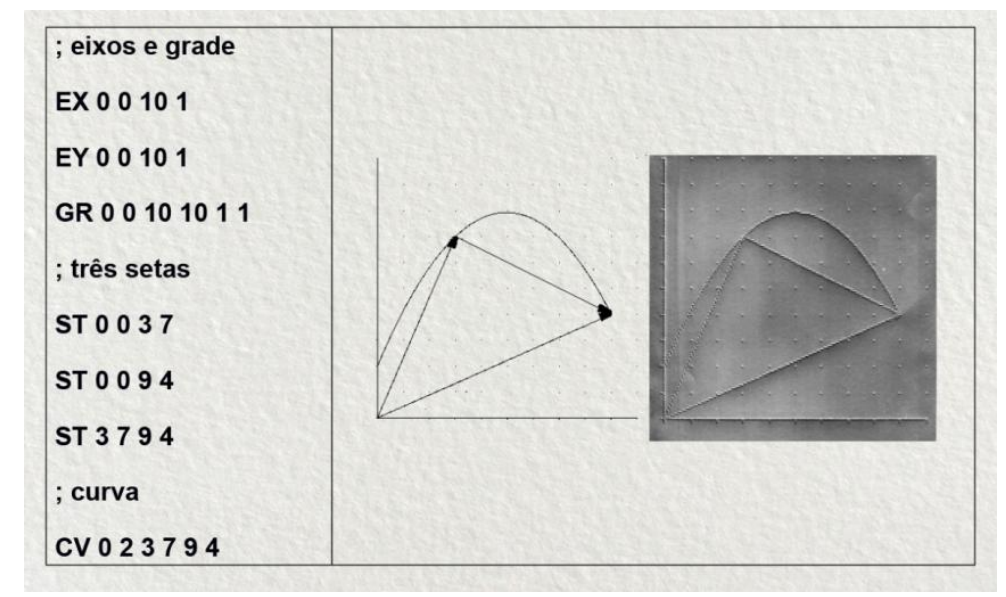

Figura 4.16: Pequeno gráfico gerado no Grafivox, impresso automaticamente em tinta e em impressora Braille.

Como se pode observar pela figura 4.16, os comandos dessa linguagem são expressos por abreviaturas de duas letras (p.ex.: RT para reta, RG para retângulo), seguidas por coordenadas (cartesianas, polares, relativas, fórmulas ou pontos descritos a partir de arquivos) que descrevem a forma indicada pelo comando. A lista de possibilidades está mostrada na figura 4.17 . 


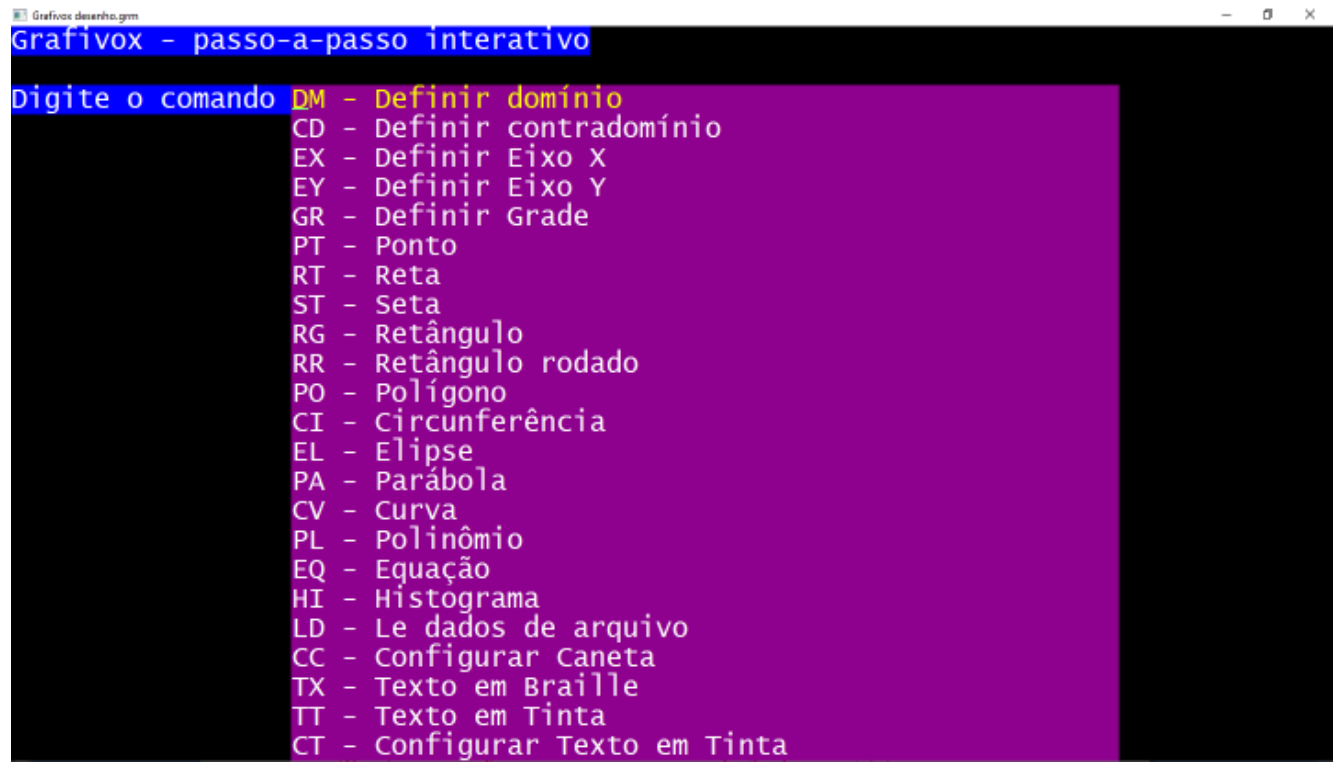

Figura 4.17: Comandos da linguagem Grafivox

O programa permite duas formas que podem ser usadas de forma misturada para criar o programa. A primeira, voltada para iniciantes, é chamada de edição interativa, em que o usuário escolhe a função com as setas (ou teclando a abreviatura), e a partir daí, se abre um formulário para preenchimento das opções, como visto na figura 4.18. Os comandos vão sendo acumulados na ordem em que são inseridos.

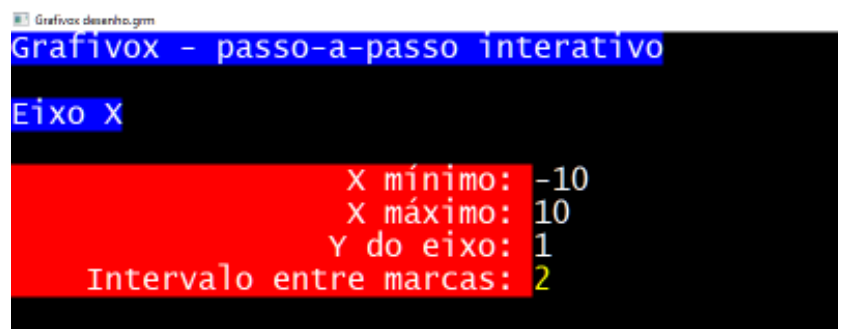

Figura 4.18: Especificação interativa dos parâmetros do comando EX (eixo X)

A segunda forma de operação é simplesmente um editor de linhas, em que o usuário tecla os comandos já com os parâmetros. Parece difícil ter que decorar tantas possibilidades de parâmetros, mas num desenho típico a variedade de comandos usados é pequena, e a ordem dos parâmetros intuitiva. Em outras palavras, nossa observação mostra que depois de poucas horas, os usuários quase não recorrem mais à opção interativa (exceto para sanar alguma dúvida).

Exercício:

Crie na linguagem Grafivox o desenho

- de dois quadrados concêntricos, de lado 2 e 4.

- dentro do quadrado mais interno trace dois segmentos de reta unindo os vértices não adjacentes.

- crie uma circunferência que toque nos quatro vértices do quadrado externo.

Visualize e imprima o gráfico criado na linguagem Grafivox no programa Intermat ou diretamente através do programa Grafivox do Dosvox.

\subsection{Uma breve discussão sobre a metodologia utilizada}


Neste texto foi apresentada a problemática de ensino e transcrição de matemática para cegos, tanto no que se refere a textos quanto gráficos. Foram apresentadas algumas alternativas com uso intensivo do computador, que podem ser aplicadas em diversas modalidades, tanto presencial quanto à distância, com ou sem estratégias de colaboração.

A base metodológica se centra no uso de um formato específico de escrita (AsciiMath), no uso de uma ferramenta de leitura de textos matemáticos (SonoraMat) e num sistema integrado interativo, totalmente acessível, que utiliza uma linguagem gráfica simples (Grafivox) Os programas apresentados são uma base mínima para o desenvolvimento acadêmico, e certamente precisam ser atualizados incessantemente ou substituídos por outras soluções, visando atender aos requisitos crescentes de inclusão acadêmica nos cursos que tem como base a matemática nas universidades.

É esperado que a aplicação das ideias mostradas neste texto em cursos preparatórios para professores de nível médio e universitários possibilite a capacitação de uma massa crítica, habilitada a utilizar e ensinar matemática com suporte tecnológico, com resultados muito mais promissores, como os que temos observado na UFRJ. De forma ainda mais conveniente, todos estarão usando uma tecnologia brasileira, simples, de distribuição gratuita e compartilhada.

Temos certeza de que, com o uso amplo destas ideias, o número de alunos que poderão ser beneficiados alcançará a marca de muitos milhares de estudantes, justificando plenamente sua aplicação no cenário brasileiro, tão carente deste tipo de ferramentas.

\section{Agradecimentos:}

Laboratório de Aplicações e Pesquisas em Tecnologia Assistiva. Projeto com a Chancela SBC.

\section{Referências:}

Anjos, D. Z. - Código matemático unificado: da definição às diferenças semióticas na conversão da tinta ao Braille - Encontro Nacional de Educação Matemática Educação Matemática na Contemporaneidade: desafios e Possibilidades - 2016, disponível em http://www.sbem.com.br/enem2016/anais/pdf/5413 2991 ID.pdf

Borges, J.A. Do Braille ao Dosvox - diferenças nas vidas dos cegos brasileiros - Rio de Janeiro: UFRJ/COPPE, 2009.

Borges, J. A. e Chagas Jr, G. J. F., Impressão Braille no Brasil: o papel do Braivox, Braille Fácil e Pintor Braille. Anais do I Simpósio Brasileiro sobre Sistema Braille, 2001.

Borges, J. A.; Borges, P. P., Matemática para alunos cegos. CIÊNCIA HOJE, v. 348, p. $1,2018$.

Borges, J. A.; Jensen, L. R. Cegos e Computador: Uma Interação que Explora o Potencial do Desenho. In: IX Simpósio Brasileiro de Informática Educativa, 1998, Recife. Anais do SBIE'98, 1998.

Cryer, H. Teaching STEM subjects to blind and partially sighted students: Literature review and resources. RNIB Centre for Accessible Information, Birmingham - 2013: Literature review \#6. 
Dias, A. F. S.; Franca, J.B.S.; Borges, M. R. S. Silva. Tecnologia Assistiva: Um Survey com portadores de deficiência visual em ambiente virtual de aprendizagem a partir do Modelo TAM. In: XVIII Conferência Internacional sobre Informática na Educação, TISE 2013, Porto Alegre

Dias, A.F.S; França, J.B.S.; Borges, J.A.S.; Silveira, J.T.C.; Carvalho. M.F.C.; Borges, M.R.S.B. Matemática, Computação e Braille: Desafios da Pedagogia, da Semiótica e da Síntese da Fala. CBIE - Congresso Brasileiro de Informática na Educação. Fortaleza , CE, 2018. https://br-ie.org/pub/index.php/sbie/article/view/8175

Ferreira, T.A.C.S - Sistema Online de Síntese de Fala em Português - Tese de Mestrado - Faculdade de Ciências e Tecnologia do Departamento de Engenharia Eletrotécnica e de Computadores - Universidade de Coimbra - 2014

Ferronato, Rubens. A construção de instrumento de inclusão no ensino da matemática. Dissertação de mestrado, UFSC, Florianópolis - SC. 2002, disponível em https://repositorio.ufsc.br/bitstream/handle/123456789/82939/PEPS2320D.pdf? sequence $=1$ \&isAllowed $=\mathrm{y}$

Gray, James (2007), "ASCIIMathML: now everyone can type MathML", MSOR Connections, 7 (3): 26-30.

Melo, A.M.. Acessibilidade e Inclusão Digital em Contexto Educacional. $3^{\circ}$ Congresso

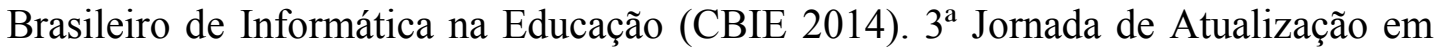
Informática na Educação (JAIE 2014). Dourados, MS.

NCE-UFRJ. (2010) "Projeto Dosvox". Núcleo de Computação Eletrônica da Universidade Federal do Rio de Janeiro. http://intervox.nce.ufrj.br/dosvox

N.F.B. (National Federation for the Blind) - The Braille Literacy Crisis in America Facing the Truth, Reversing the Trend, Empowering the Blind; Jernigan Institute; March 26, 2009.

Silveira, H.M.; Martini, L.C. MATVOX: um aplicativo para deficientes visuais que proporciona a implementação de algoritmos e cálculos matemáticos em um editor de texto. Brazilian Symposium on Computers in Education - Simpósio Brasileiro de Informática na Educação - SBIE, Campinas - SP. 2011.

Souza, J. B. - O que vê a cegueira - A escrita Braille e sua natureza semiótica. - Ed. UFPB -2017 . 


\section{Biografia Resumida dos Autores:}

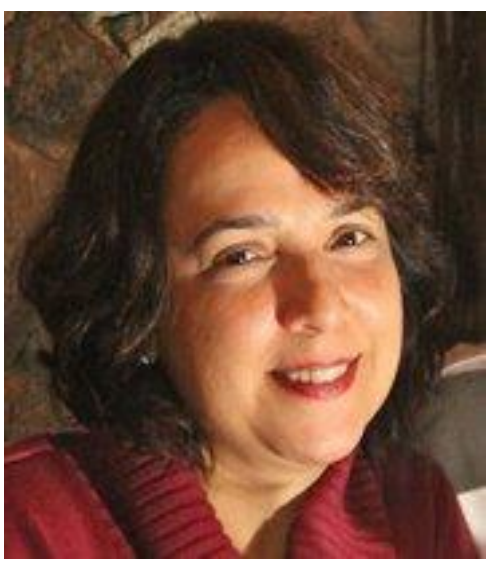

Angélica F. S. Dias possui Doutorado em Informática pela Universidade Federal do Rio de Janeiro (PPGI - 2018) com ênfase em Gestão de Sistemas Complexos. Mestre em Sistemas de Informação pela UFRJ. MBA em E-Business pela COPPEAD e DBM - Inteligência e Database Marketing/NCE/UFRJ. Aperfeiçoamento em Gerência Avançada de Projetos/UFRJ. Graduação em Processamento de Dados/UNESA. Foi Diretora da Área de Extensão do Instituto Tércio Pacitti/UFRJ, Coordenadora Acadêmica dos Cursos de pós-graduação no NCE/UFRJ (2003-2005). Professora Convidada pelos: Instituto de Economia, Instituto Tércio Pacitti (NCE) e Programa de PósGraduação em Informática (PPGI). Foi Professora convidada do Coppead/UFRJ, Ministério da Educação, IBMEC e Cecierj. Tem experiência nas áreas de Administração Pública, Gerência de Projetos, Ciência da Computação e Educação. Atualmente é pesquisadora e Coordenadora de Extensão pelo Instituto Tércio Pacitti/NCE/UFRJ. Temas de interesse: Gestão de Conhecimento, Trabalho e Aprendizagem Cooperativa apoiada por computador (CSCW e CSCL), Tecnologia Assistiva, Economia Circular com ênfase em Sustentabilidade, Gestão Estratégica da Informação e Educação. Artigos e capítulos de livros publicados em conferências nacionais e internacionais.

\section{Lattes: http://lattes.cnpq.br/8795875378897586}

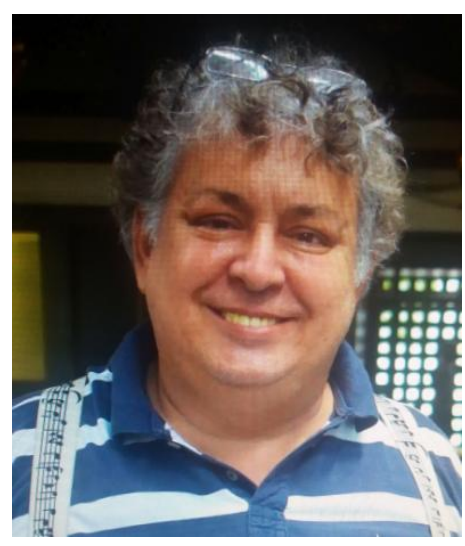

José Antonio dos Santos Borges possui graduação em Matemática mod. Informática pela Universidade Federal do Rio de Janeiro (1980), graduação em Piano - Conservatório Brasileiro de Música (1977), mestrado (1988) e doutorado em Engenharia de Sistemas e Computação pela COPPE/UFRJ (2009). Atualmente é Coordenador da Pós-graduação em História das Ciências e das Técnicas e Epistemologia da UFRJ - É analista de Tecnologia da Informação no Instituto Tércio Pacitti da UFRJ (NCE/UFRJ), onde trabalha desde 1975. É especialista em Tecnologia Assistiva, tendo desenvolvido grande 


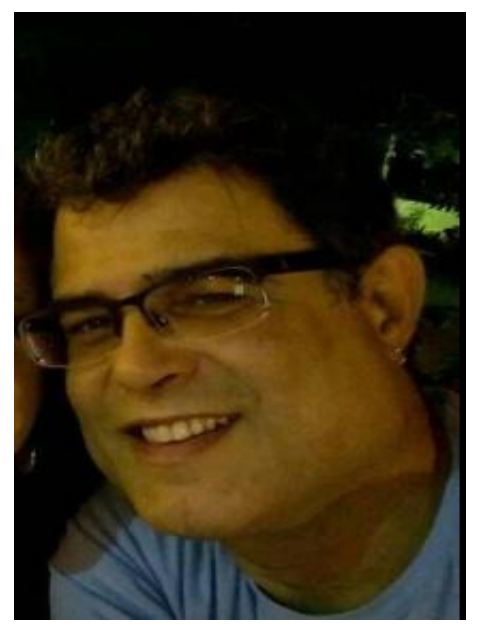

quantidade de sistemas para acesso de pessoas com deficiência aos computadores. Atuou também em síntese de voz, sistemas para cartografia tátil adaptada, computação gráfica e CAD para microeletrônica. Premiado duas vezes com a medalha de Excelência Acadêmica do Instituto de Matemática da UFRJ. Tem diversos artigos e capítulos de livros publicados em conferências nacionais e internacionais.

Lattes: $\underline{\text { http://lattes.cnpq.br/1957526921210046 }}$

Júlio Tadeu Carvalho da Silveira possui graduação em Informática (Bacharelado) pela Universidade Federal do Rio de Janeiro (1990) e mestrado em Engenharia de Sistemas e Computação pela COPPE/UFRJ (1996). Atualmente é Técnico de Tecnologia da Informação, no Instituto Tércio Pacitti de Aplicações e Pesquisas Computacionais/NCE, da Universidade Federal do Rio de Janeiro e Professor Assistente do Centro Universitário Carioca. Tem experiência na área de Ciência da Computação. Atuando principalmente nos seguintes temas: Robótica, Planejamento de Trajetória, Trajetória Evitando Obstáculos. Tem diversos artigos publicados em conferências nacionais e internacionais.

Lattes: http://lattes.cnpq.br/7081474226160086 